\title{
Incremental Health Care Burden of Bleeding Among Patients with Venous Thromboembolism in the United States
}

\author{
Alpesh Amin, MD; Amanda Bruno, PhD, MPH; Jeffrey Trocio, MPH; Jay Lin, PhD, MBA;
} and Melissa Lingohr-Smith, PhD

\begin{abstract}
BACKGROUND: The health care and economic burden of venous thromboembolism (VTE) has been evaluated in regard to acute VTE, VTE recurrence, and some VTE complications, such as postthrombotic syndrome, but the cost burden attributed to bleedings is not well understood.

OBJECTIVE: To evaluate health care resource utilization and costs associated with major bleeding (MB) and clinically relevant nonmajor bleeding (CRNMB) among a large U.S. commercially and Medicare-insured population with VTE.

METHODS: Patients ( $\geq 18$ years of age, continuously insured) with a diagnosis of VTE between January 1, 2008, and December 31, 2011, were identified from the Truven Health Analytics Commercial and Medicare MarketScan databases. Patients who did not have any bleedings during the study period were grouped into a no-bleedings cohort and a random date after VTE diagnosis was selected as the index date. VTE patients who experienced MB within 1 year of the initial VTE diagnosis were grouped into a MB cohort, and patients without MB but with CRNMB were grouped into a CRNMB cohort. Baseline patient demographics and clinical characteristics were determined for study cohorts. All-cause and bleeding-related health care resource utilization and costs (inflation adjusted to 2013 level) during a 12-month followup period after the index date of the initial bleeding event were measured and compared. Descriptive statistics were used to evaluate differences in demographics, clinical characteristics, and unadjusted health care resource utilization and costs of patient cohorts. Multivariable generalized linear models were used to evaluate incremental health care costs of bleedings after adjusting for key patient characteristics.
\end{abstract}

RESULTS: Among the 112,885 patients identified with a VTE diagnosis, $14 \%$ $(n=15,897)$ had MB and 14\% $(n=15,842)$ had CRNMB; $72 \%(n=81,146)$ had neither of these events occur during the study period. The mean ages of the MB and CRNMB cohorts were both 63.6 years, while the mean age of the no-bleedings cohort was significantly lower at 59.6 years $(P<0.001)$. Mean Charlson Comorbidity Index scores were highest for the MB cohort (3.2), followed by those of the CRNMB cohort (2.5) and the no-bleedings cohort (1.6). The MB cohort had the greatest proportion of patients with an initial VTE event of pulmonary embolism only (23.5\%), followed by that of the CRNMB cohort (20.2\%), and the no-bleedings cohort (16.7\%). For MB and CRNMB cohorts, the total mean bleeding-related inpatient and outpatient costs during the follow-up period were $\$ 49,779(\mathrm{SE}=\$ 820)$ and $\$ 2,187$ (\$89), respectively. After adjustment for key patient characteristics, the estimated mean differences in total bleeding-related medical costs were $\$ 45,367(\$ 1,853)$ for patients with MB and $\$ 2,140$ (\$88) for patients with CRNMB versus patients with no bleedings.

CONCLUSIONS: Among patients with VTE diagnosis in the United States, approximately $28 \%$ have a bleeding event within 1 year of VTE diagnosis, and about half of these patients experience MB. Patients with MB have greatly elevated health care costs.

J Manag Care Spec Pharm. 2015;21(10):965-72

Copyright $\odot 2015$, Academy of Managed Care Pharmacy. All rights reserved.

\section{What is already known about this subject}

Venous thromboembolism (VTE), including deep vein thrombosis and pulmonary embolism, is the third most common cause of vascular disease-related deaths in the United States.

To prevent VTE, recurrence patients who experience an acute event are recommended treatment with anticoagulation therapy; however, anticoagulation therapy increases the risk of bleedings. The health care and economic burden of VTE has been evaluated in regard to acute VTE, VTE recurrence, and some VTE complications, such as postthrombotic syndrome, but that attributed to bleedings is not well understood.

\section{What this study adds}

The results of this retrospective database study of 112,885 patients with VTE show that clinically relevant nonmajor bleeding (CRNMB) and major bleeding (MB) are relatively frequent, with a combined annual rate of $28 \%$.

Based on this large retrospective database study, the average annual incremental bleeding-related medical costs of $\mathrm{MB}$ are $\$ 45,367$, while those of CRNMB are much lower at $\$ 2,140$.

Major bleeding is associated with a substantial medical cost and its clinical impact is severe, and thus represents a significant burden among VTE patients in the real-world setting.

T enous thromboembolism (VTE), including deep vein thrombosis (DVT) and pulmonary embolism (PE), is the third most common cause of vascular diseaserelated deaths and was estimated in 2011 to annually cost between $\$ 13.5$ and $\$ 27.2$ billion in the United States. ${ }^{1,2}$ VTE is considered a chronic disease as it has a high chance of recurring, with observational cohort studies reporting cumulative recurrence incidences of 25\% after 5 years and 30\% after 10 years. $^{3,4}$ To prevent VTE recurrence, patients who experience an acute event are recommended treatment with anticoagulation therapy; however, anticoagulation therapy increases the risk of bleedings. ${ }^{5}$

Current American College of Chest Physicians (ACCP) Antithrombotic Therapy and Prevention of Thrombosis, 9th Edition, Evidence-Based Clinical Practice Guidelines recommend initial treatment for acute DVT or PE with parenteral lowmolecular weight heparin (LMWH) or anticoagulation with 
TABLE 1 Baseline Demographics and Clinical Characteristics of Venous Thromboembolism Patients with Major Bleeding, Clinically Relevant Nonmajor Bleeding, and No Bleedings

\begin{tabular}{|c|c|c|c|c|c|c|c|}
\hline & \multicolumn{2}{|c|}{ MB } & \multicolumn{2}{|c|}{ CRNMB } & \multicolumn{2}{|c|}{ No Bleedings } & $P$ Value $^{\mathrm{a}}$ \\
\hline Total patient count & \multicolumn{2}{|c|}{15,897} & \multicolumn{2}{|c|}{15,842} & \multicolumn{2}{|c|}{81,146} & \\
\hline \multicolumn{8}{|l|}{ Age, years } \\
\hline Mean (SD) & 63.6 & $(16.1)$ & 63.6 & (15.6) & 59.6 & (16.2) & $<0.001$ \\
\hline Age group, years, n (\%) & & & & & & & $<0.001$ \\
\hline $18-29$ & 446 & $(2.8)$ & 264 & $(1.7)$ & 2,573 & $(3.2)$ & \\
\hline $30-39$ & 767 & $(4.8)$ & 827 & $(5.2)$ & 6,185 & $(7.6)$ & \\
\hline $40-49$ & 1,623 & $(10.2)$ & 1,840 & $(11.6)$ & 12,868 & $(15.9)$ & \\
\hline $50-59$ & 3,514 & $(22.1)$ & 3,548 & $(22.4)$ & 20,545 & $(25.3)$ & \\
\hline $60-64$ & 2,440 & (15.4) & 2,248 & $(14.2)$ & 11,181 & (13.8) & \\
\hline $65-69$ & 1,002 & $(6.3)$ & 1,053 & $(6.7)$ & 4,441 & $(5.5)$ & \\
\hline $70-74$ & 1,413 & $(8.9)$ & 1,483 & $(9.4)$ & 5,894 & $(7.3)$ & \\
\hline $75-79$ & 1,561 & $(9.8)$ & 1,601 & $(10.1)$ & 5,979 & $(7.4)$ & \\
\hline$\geq 80$ & 3,131 & $(19.7)$ & 2,978 & (18.8) & 11,480 & $(14.2)$ & \\
\hline \multicolumn{7}{|l|}{ Gender } & 0.002 \\
\hline Male, n (\%) & 7,257 & $(45.7)$ & 7,546 & $(47.6)$ & 37,751 & $(46.5)$ & \\
\hline Female, $\mathrm{n}(\%)$ & 8,640 & $(54.4)$ & 8,296 & $(52.4)$ & 43,395 & $(53.5)$ & \\
\hline \multicolumn{7}{|l|}{ U.S. geographic region, $\mathbf{n}(\%)$} & $<0.001$ \\
\hline Northeast & 2,526 & $(15.9)$ & 2,646 & $(16.7)$ & 12,374 & $(15.3)$ & \\
\hline North central & 4,975 & $(31.3)$ & 4,857 & $(30.7)$ & 25,034 & (30.9) & \\
\hline South & 5,326 & $(33.5)$ & 5,453 & $(34.4)$ & 28,815 & $(35.5)$ & \\
\hline West & 3,044 & $(19.2)$ & 2,859 & (18.1) & 14,761 & (18.2) & \\
\hline Unknown & 26 & $(0.2)$ & 27 & $(0.2)$ & 162 & $(0.2)$ & \\
\hline \multicolumn{8}{|l|}{ Charlson Comorbidity Index } \\
\hline Mean (SD) & 3.2 & (2.8) & 2.5 & $(2.6)$ & 1.6 & $(2.1)$ & $<0.001$ \\
\hline \multicolumn{7}{|l|}{ CCI group, $\mathbf{n}(\%)$} & $<0.001$ \\
\hline 0 & 2,326 & $(14.6)$ & 3,728 & $(23.5)$ & 31,717 & $(39.1)$ & \\
\hline $1-2$ & 5,649 & $(35.5)$ & 6,011 & $(37.9)$ & 30,173 & $(37.2)$ & \\
\hline $3-4$ & 4,065 & $(25.6)$ & 3,416 & $(21.6)$ & 11,943 & $(14.7)$ & \\
\hline$\geq 5$ & 3,857 & $(24.3)$ & 2,687 & $(17.0)$ & 7,313 & $(9.0)$ & \\
\hline \multicolumn{7}{|l|}{ Baseline VTE events, n (\%) } & $<0.001$ \\
\hline Deep vein thrombosis only & 9,449 & $(59.4)$ & 9,928 & $(62.7)$ & 54,966 & $(67.7)$ & \\
\hline $\begin{array}{l}\text { Deep vein thrombosis/pulmo- } \\
\text { nary embolism }\end{array}$ & 2,711 & $(17.1)$ & 2,716 & $(17.1)$ & 12,631 & $(15.6)$ & \\
\hline Pulmonary embolism only & 3,737 & $(23.5)$ & 3,198 & $(20.2)$ & 13,549 & $(16.7)$ & \\
\hline \multicolumn{8}{|c|}{ Total all-cause health care resource payments (inpatient + outpatient $+\mathrm{Rx}$ ) } \\
\hline Mean (SD) & $\$ 70,448$ & $(\$ 121,811)$ & $\$ 53,836$ & $(\$ 91,493)$ & $\$ 40,873$ & $(\$ 72,902)$ & $<0.001$ \\
\hline
\end{tabular}

rivaroxaban, and additional anticoagulation therapy (such as a vitamin $\mathrm{K}$ antagonist (VKA), LMWH, or rivaroxaban) for 3 months or longer depending on bleeding risk and whether the event was provoked, unprovoked, or associated with active cancer. ${ }^{5}$ Anticoagulation therapy with the most commonly used VKA, warfarin, has limitations in that warfarin has variable pharmacokinetics and several drug-drug and drugfood interactions, and requires frequent monitoring and dose adjustments. ${ }^{6}$ Additionally, LMWH is administered parenterally, complicating its long-term use for many patients and increasing its cost of use. ${ }^{6}$
Since the ACCP guidelines were developed, 3 other new oral anticoagulants (NOACs) in addition to rivaroxaban have been approved by the U.S. Food and Drug Administration (FDA) for treatment of acute symptomatic VTE. These include dabigatran, apixaban, and edoxaban. The 4 NOACs have all been shown to be noninferior to standard therapies for treatment of acute symptomatic VTE, and some are associated with reduced bleeding risk..$^{7-13}$ Moreover, NOACs are easy to administer, have a rapid onset of action, and have predictable pharmacokinetics, eliminating the need for monitoring. ${ }^{6}$ 


\begin{tabular}{|c|c|c|c|}
\hline $\begin{array}{l}\text { Bleed-Re } \\
\text { Utilizatio } \\
\text { Venous } \\
\text { with Ma } \\
\text { Relevant } \\
\text { the 12-M }\end{array}$ & \multicolumn{3}{|c|}{$\begin{array}{l}\text { Bleed-Related Health Care Resource } \\
\text { Utilization and Associated Costs of } \\
\text { Venous Thromboembolism Patients } \\
\text { with Major Bleeding and Clinically } \\
\text { Relevant Nonmajor Bleeding During } \\
\text { the 12-Month Follow-up Period }\end{array}$} \\
\hline & $\begin{array}{c}\text { MB } \\
\text { Mean (SD) }\end{array}$ & & $\begin{array}{l}\mathrm{NMB} \\
(\mathrm{SD})\end{array}$ \\
\hline Number of hospitalizations & $1.14 \quad(0.83)$ & 0.03 & $(0.18)$ \\
\hline Total length of stay (days) & $10.7 \quad(17.2)$ & 0.2 & $(1.7)$ \\
\hline Total hospital payments & $\$ 48,036(\$ 102,476)$ & $\$ 819$ & $(\$ 9,968)$ \\
\hline Number of outpatient claims & $5.89 \quad(16.33)$ & 6.75 & $(12.13)$ \\
\hline Total outpatient payments & $(\$ 7,088)$ & $\$ 1,368$ & $(\$ 4,756)$ \\
\hline Number of office visit claims & $(4.08)$ & 2.15 & $(4.97)$ \\
\hline Total office visit payments & $(\$ 1,471)$ & $\$ 222$ & $(\$ 521)$ \\
\hline Number of ED claims & $(1.61)$ & 0.41 & $(2.01)$ \\
\hline Total ED payments & $\$ 47 \quad(\$ 415)$ & $\$ 102$ & $(\$ 535)$ \\
\hline $\begin{array}{l}\text { Total health care resource } \\
\text { payments (inpatient + outpatient) }\end{array}$ & $\$ 49,779(\$ 103,352)$ & $\$ 2,187$ & $(\$ 11,221)$ \\
\hline \multicolumn{4}{|c|}{$\begin{array}{l}\text { Note: Analysis of variance was used for the statistical comparison. All P values } \\
\text { were }<0.001 \text { for the comparison of the } 2 \text { study cohorts. } \\
C R N M B=\text { clinically relevant nonmajor bleeding; } E D=\text { emergency department; } \\
M B=\text { major bleeding; } S D=\text { standard deviation. }\end{array}$} \\
\hline
\end{tabular}

In the NOAC versus standard therapy acute VTE clinical trials-RE-COVER, RE-COVER II, EINSTEIN-DVT, EINSTEIN-PE, AMPLIFY—and the Hokusai-VTE trial, patient populations may differ from those in real-world settings, making it difficult to understand the potential value of implementing the NOACs and their impact on patient outcomes. ${ }^{7-13}$ The health care and economic burden of VTE has been evaluated in regard to acute VTE, VTE recurrence, and some VTE complications, such as postthrombotic syndrome, but the cost burden attributed to bleedings has not been well examined. ${ }^{14,15}$ Therefore, in this study we evaluated health care resource utilization and costs associated with major bleeding (MB) and clinically relevant nonmajor bleeding (CRNMB) among patients with VTE.

\section{Methods}

$\overline{\text { This study was a retrospective cohort analysis that evaluated }}$ health care resource utilization and annual incremental costs (i.e., total payments) associated with bleedings among patients with VTE.

\section{Study Population}

Patients ( $\geq 18$ years of age) with a diagnosis of VTE (International Classification of Diseases, Ninth Revision, Clinical Modification [ICD-9-CM] codes 451.11, 451.19, 451.2x, 451.81, 451.83, 451.84, 451.89, 451.9x, 453.2x, 453.40, 453.41, 453.42, 453.8x, $453.82,453.83,453.84,453.85,453.86,453.87,453.88$, 453.89, and 453.9x for DVT, 415.1x for PE) were identified from the Truven Health Analytics Commercial and Medicare
MarketScan databases between January 1, 2008, and December 31, 2011. Encompassing > 50 million employees, spouses, and dependents located in all 10 U.S. census regions, the databases consist of health care claims data from approximately 100 insurance companies, Blue Cross Blue Shield plans, and thirdparty administrators. The claims data includes inpatient and outpatient information, laboratory data, and detailed hospital drug data, reflecting real-world treatment patterns and costs.

The database facilitates longitudinal studies by providing integrated standardized data for patients spanning extensive time periods. In compliance with the Health Insurance Portability and Accountability Act of 1996, the database consists of fully deidentified data sets, with synthetic identifiers applied to patient-level and provider-level data to protect the identities of both the patients and data contributors.

VTE patients who experienced MB within 1 year of the initial VTE diagnosis were grouped into an MB cohort, and patients without MB but with CRNMB were grouped into a CRNMB cohort. ICD-9-CM codes were used to identify patients with $\mathrm{MB}$ and $\mathrm{CRNMB}$ events, as previously described by Deitelzweig et al. ${ }^{16}$ The first date of the corresponding MB or CRNMB diagnosis was used as the index date for MB or CRNMB patients. Patients who did not have any bleedings in the 1 year following the initial VTE diagnosis were grouped into a no-bleedings cohort, and a random date during the 1 year after the initial VTE diagnosis was selected as the index date. All persons within the study cohorts were required to have continuous medical and prescription coverage during the 12-month periods before (baseline period) and after (follow-up period) the index date.

\section{Baseline Demographics and Clinical Characteristics}

Demographics including age, gender, U.S. geographic region, and health plan type, and clinical characteristics including Charlson Comorbidity Index (CCI) score, initial VTE event type (i.e., DVT only, DVT and PE, PE only), and total all-cause resource (inpatient, outpatient, and pharmacy use) costs were measured for the study cohorts.

\section{Outcome Measures}

All-cause and bleeding-related health care resource utilization and payments during the 12-month follow-up period were measured and compared. The evaluated health care resources included the number of hospitalizations and hospital length of stay and the number of outpatient medical service claims, also grouped by number of office visits and number of emergency department (ED) visits. The total health care costs and net payer cost (excluding patient copay and coinsurance) were measured for all evaluated health care resource uses. All costs were inflation-adjusted to 2013 cost levels using the Medical Care component of the Consumer Price Index. ${ }^{17}$ 


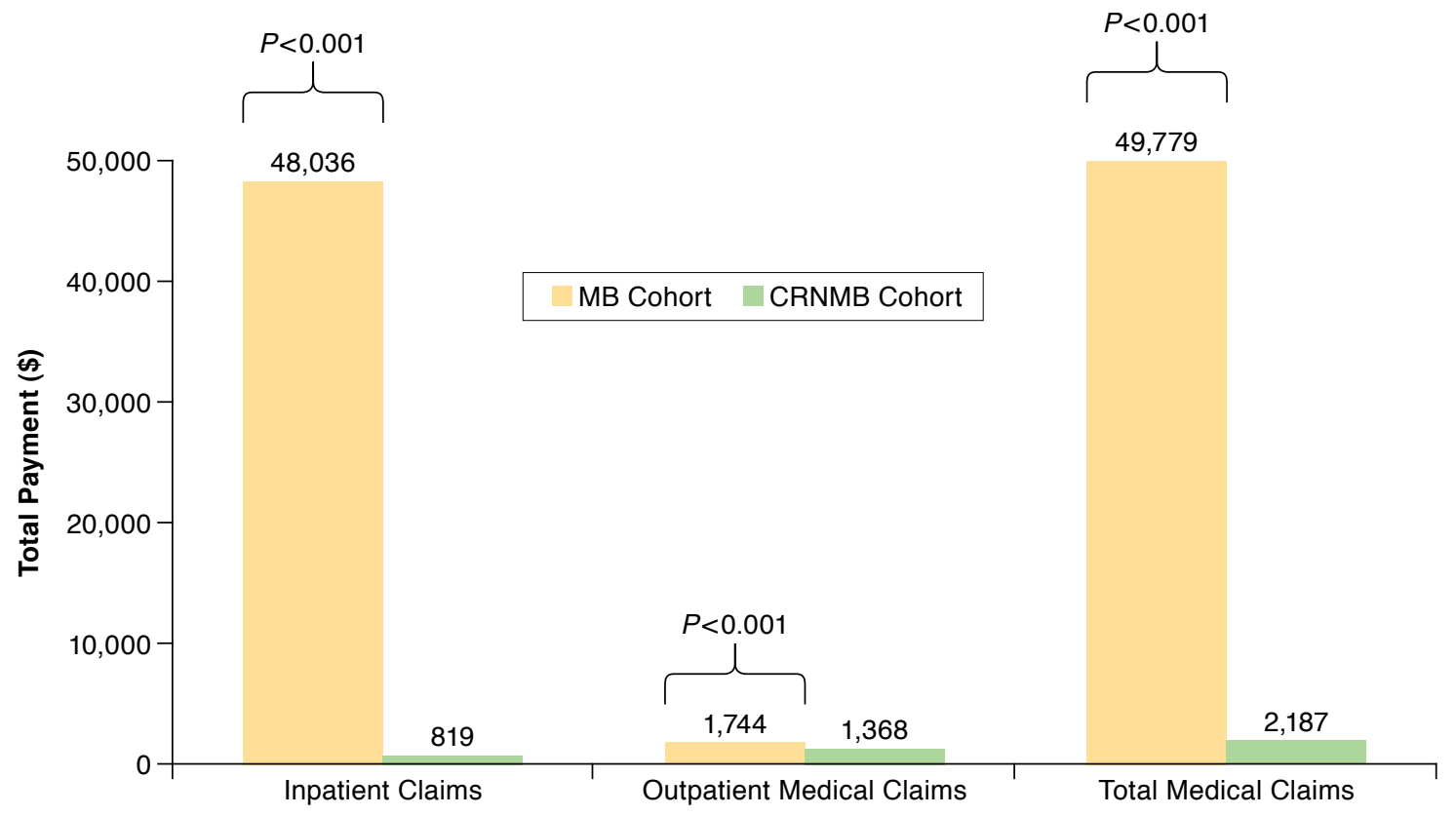

$C R N M B=$ clinically relevant nonmajor bleeding; $M B=$ major bleeding.

\section{Statistical Analyses}

Descriptive statistics were used to evaluate differences in demographics, clinical characteristics, and unadjusted health care resource use and costs of patient cohorts. T-tests and chi-square tests were used to detect statistically significant differences in continuous and categorical variables, respectively. Multivariable generalized linear models were used to evaluate incremental health care payments after adjusting for key patient characteristics, which included age, gender, baseline VTE type, CCI score, U.S. geographic region, and baseline total all-cause resource payment. A critical value of 0.05 was used to determine statistical significance. All statistical analyses were carried out using SAS software package 9.3 (SAS Institute Inc., Cary, NC).

\section{Results}

\section{Demographics and Clinical Characteristics}

Among the 112,885 patients identified with a VTE diagnosis, $14 \%(n=15,897)$ had MB and $14 \%(n=15,842)$ had CRNMB, and $72 \%(n=81,146)$ had neither of these events occur during the 12-month follow-up period. All evaluated demographics and clinical characteristics are presented in Table 1. The mean ages of the MB and CRNMB cohorts were both 63.6 years, while the mean age of the no-bleedings cohort was significantly less at 59.6 years $(P<0.001)$. The most common types of health plans for all 3 study cohorts were preferred provider organizations (46.7\%-50.3\%), comprehensive health plans (21.3\%$27.0 \%$ ), and health maintenance organizations (10.4\%-13.1\%).

Mean CCI scores were highest for the MB cohort (3.2), followed by that of the CRNMB cohort (2.5) and the no-bleedings cohort (1.6). The MB cohort had the greatest proportion of patients with an initial VTE event of PE only (23.5\%), followed by that of the CRNMB cohort (20.2\%) and the no-bleedings cohort (16.7\%). Baseline total costs for inpatient and outpatient care and pharmacy use for all causes were statistically different among the MB cohort $(\$ 70,448)$, the CRNMB cohort $(\$ 53,836)$, and the no-bleedings cohort $(\$ 40,873)$.

\section{Unadjusted Health Care Resource Utilization and Associated Costs of VTE Patients}

The mean numbers of bleeding-related hospitalizations (1.14 vs. $0.03, P<0.001)$ and hospital length of stay $(10.7$ vs. 0.2 days, $P<0.001)$ were significantly greater for the $\mathrm{MB}$ cohort in comparison to the CRNMB cohort during the follow-up period (Table 2). The mean annual total cost of bleedingrelated hospitalizations was $\$ 48,036$, while that for CRNMB was $\$ 819$ (Table 2, Figure 1). Mean annual total costs for bleeding-related outpatient medical service claims were $\$ 1,744$ for the MB cohort and $\$ 1,368$ for the CRNMB cohort (Table 2, Figure 1). The mean number of bleeding-related outpatient 


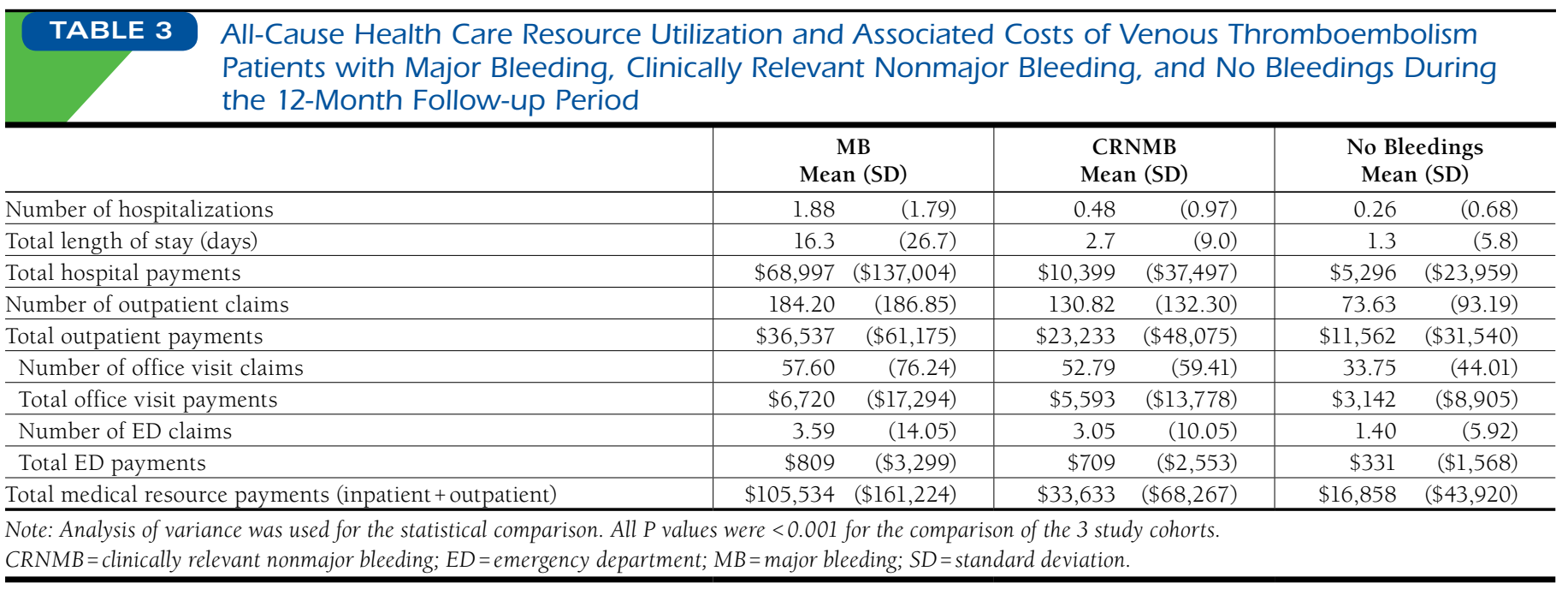

medical service claims was less for the MB cohort than for the CRNMB cohort (5.89 vs. $6.75, P<0.001)$. The combined mean total bleeding-related inpatient and outpatient medical service claim costs were $\$ 49,779$ for the MB cohort and $\$ 2,187$ for the CRNMB cohort (Table 2, Figure 1).

For patients in the MB cohort, bleeding-related health care resource utilization cost accounted for $47 \%$ of the total all-cause inpatient and outpatient medical service costs, which were $\$ 105,534$ (Table 3). For the CRNMB cohort, the mean total allcause inpatient and outpatient medical service costs were much lower in comparison to the MB cohort at $\$ 33,633$ (Table 3).

\section{Adjusted Health Care Resource Utilization and Associated Costs of VTE Patients}

After adjustment for key patient characteristics, the estimated mean differences of the patients with bleeds versus patients in the no-bleedings cohort in total annual inpatient, outpatient medical services, and pharmacy costs were $\$ 73,862$ (standard error $[\mathrm{SE}]=\$ 1,332 ; 95 \%$ confidence interval $[\mathrm{CI}]=\$ 71,297$ $\$ 76,519$ ) for patients with $\mathrm{MB}$ and $\$ 12,138$ (SE $=\$ 251 ; 95 \%$ $\mathrm{CI}=\$ 11,655-\$ 12,641$ ) for patients with CRNMB (Figure 2). The estimated mean differences of the patients with bleedings versus patients in the no-bleedings cohort in total annual inpatient and outpatient medical services were $\$ 72,813$ $(\mathrm{SE}=\$ 1,421 ; 95 \% \mathrm{CI}=\$ 70,080-\$ 75,652)$ for patients with $\mathrm{MB}$ and $\$ 11,437(\mathrm{SE}=\$ 253 ; 95 \% \mathrm{CI}=\$ 10,952-\$ 11,943)$ for patients with CRNMB (Figure 2). The estimated mean differences of the patients with bleedings versus patients in the no-bleedings cohort in total bleeding-related annual inpatient and outpatient medical service costs were $\$ 45,367$ ( $\mathrm{SE}=\$ 1,853 ; 95 \% \mathrm{CI}=\$ 41,876-\$ 49,149)$ for patients with $\mathrm{MB}$ and $\$ 2,140$ ( $\mathrm{SE}=\$ 88 ; 95 \% \mathrm{CI}=\$ 1,974-\$ 2,320)$ for patients with CRNMB (Figure 2). At the adjusted level, bleeding-related costs accounted for $62 \%$ and $19 \%$ of total all-cause inpatient and outpatient medical service costs for the MB and CRNMB cohorts, respectively.

\section{Discussion}

The results of this retrospective database study of 112,885 patients with VTE show that CRNMB and MB are relatively frequent with a combined annual rate of $28 \%$, and individual rates of $14 \%$ for both. The rates of CRNMB and MB in the real-world setting are higher than the $<2 \%$ for $\mathrm{MB}$ and $4 \%-9 \%$ for CRNMB reported in closely controlled clinical trials. ${ }^{7-13,18}$ However, a previous study conducted in the community setting of Worcester, Massachusetts, reported a MB rate of 12\%$13 \%$ per year and a cumulative incidence of approximately $8 \%$ in the month following the initial diagnosis of VTE. ${ }^{19}$ The much higher rate of $\mathrm{MB}$ found in real-world settings may be attributed to many factors, including VTE patients being of greater age and having more comorbidity than that observed for patients participating in clinical trials. ${ }^{19}$ In our study, the mean age of both the MB and CRNMB cohorts was 63.6 years, and approximately $20 \%$ of either cohort was $>80$ years. The mean age of the cohort with no bleedings was 59.6 years and more similar to that observed for patients in the NOAC versus standard therapy acute VTE clinical trials. ${ }^{7-13}$ Comorbidity as measured by the CCI was highest for the MB cohort and lowest for the cohort with no bleedings. Also the MB cohort had the largest proportion of patients who experienced a PE. These descriptive data of our study cohorts are in line with previously identified risk factors of bleedings. 5,6

We found that the mean annual total medical costs of MB were $\$ 45,367$ after adjusting for differences in key patient characteristics, and that these costs represented $62 \%$ of the annual costs of inpatient and outpatient medical care for all causes. The adjusted mean annual medical costs of CRNMB were much lower at $\$ 2,140$. Another study in which the costs of bleedings 


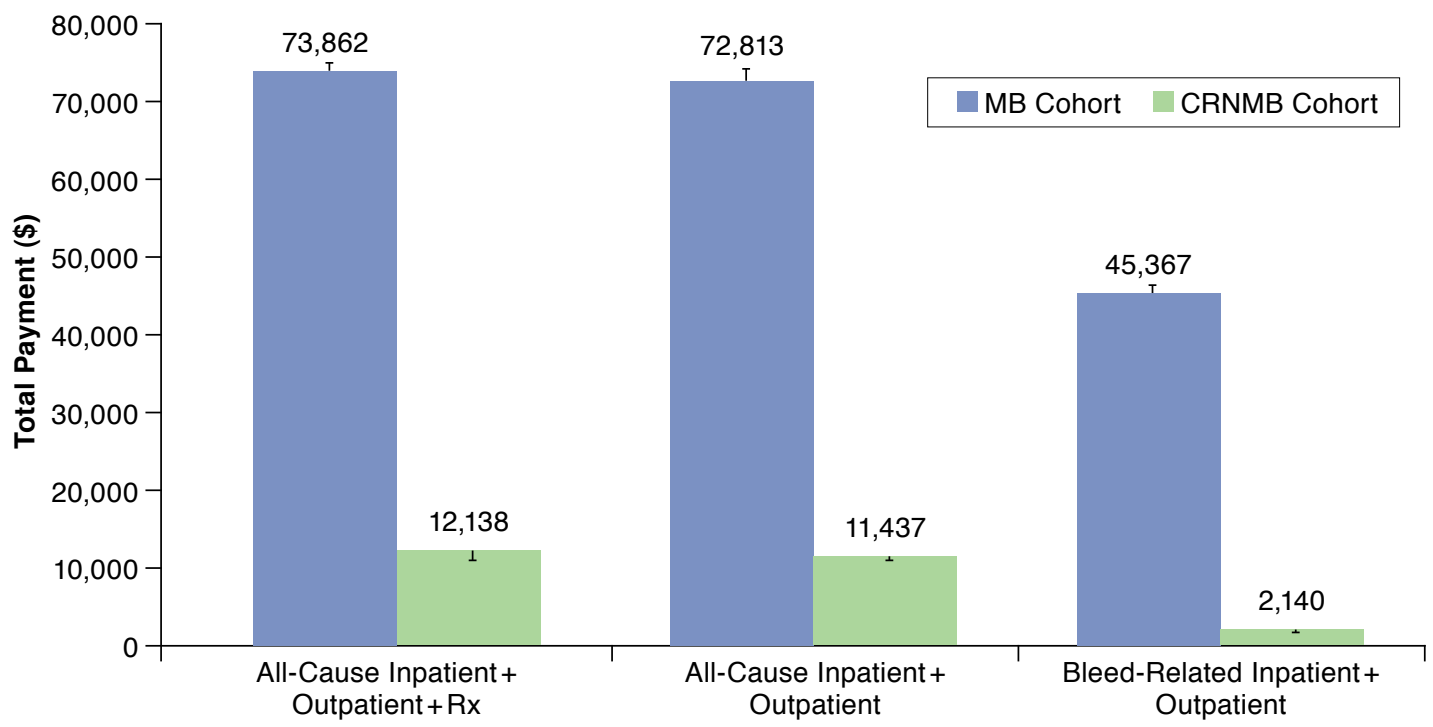

All $P$ values were $<0.05$ for the comparisons of the $M B$ and $C R N M B$ cohorts versus the no-bleedings cohort. Error bars represent standard error. $C R N M B=$ clinically relevant nonmajor bleeding; $M B=$ major bleeding; $R x=$ prescription .

were evaluated among patients with acute symptomatic VTE was conducted by Bullano et al. on a U.S. managed care population of 2,147 VTE patients identified between 1998 and 2000. ${ }^{20}$ In this study, bleedings were grouped together and included minor bleedings. Bullano et al. reported a frequency of $7.9 \%$ for bleedings that required hospitalization, which had an average cost of $\$ 15,339$ per event..$^{20}$ The cost per MB event did not include the cost of any other readmissions or other incremental costs due to bleeding as a complication (i.e., secondary diagnosis). Thus, this reported cost may underestimate the total costs to payers related to bleeding. A study conducted on 119,764 patients with atrial fibrillation reported an event rate of $7.6 \%$ for $\mathrm{MB}$ and that the average annual cost of a patient with a MB event was $\$ 29,965$ in 2006 dollars. ${ }^{21}$ In another retrospective database analysis of 48,260 patients with atrial fibrillation, Deitelzweig et al. reported a higher rate of $10.4 \%$ for MB. ${ }^{16}$

Although real-world analyses of bleeding event rates differ to some extent, it is noteworthy that they are all considerably higher than those reported in clinical trials. ${ }^{7-13,16,18}$ Not only is the cost of an MB event substantial, but also the clinical impact is severe, as case fatality rates among VTE patients have been reported as high as $33 \%$ within the first 30 days after an MB event. ${ }^{22}$ The high prevalence and high cost of MB show that it is a significant burden among VTE patients and there is a need to define better therapies to manage VTE patients in aspects of both VTE recurrence risk and bleeding risk.

In real-world settings, 5-year VTE recurrence incidences range between $21.5 \%$ and $29.1 \%{ }^{3,23}$ Health care providers of VTE patients must assess the risk-benefit ratio of anticoagulation therapy and strike a balance between prevention of VTE recurrence and bleeding complications. ${ }^{24}$ This is difficult, as some of the risk factors for VTE recurrence, such as greater age and comorbidity, are also risk factors for MB. Increasing the pharmacological armamentarium for the treatment of VTE may assist in the decision-making process of choosing the anticoagulant treatment with the best benefit-risk profile for a particular patient. The NOACs that demonstrate efficacy in reducing VTE recurrence risk similar to that of standard therapies but that are associated with a lower risk of bleeding will likely be valuable pharmacological tools to improve the outcomes of patients with VTE.

\section{Limitations}

How well rates of MB and CRNMB identified in this retrospective database analysis compare with such events identified from the clinical trials may warrant further evaluation. Claims in the MarketScan databases are subject to coding errors, coding for the purpose of rule-out rather than actual disease, and undercoding, either by the health care provider or due to limitations imposed by the database. The analysis only evaluated direct medical costs, and the long-term burden of clinical events, indirect costs, and quality of life were not taken into consideration. The observational design was susceptible to various biases, such as information or classification bias (e.g., 
identification of false-positive VTE events). The MarketScan databases are based on large convenience samples and as the populations are not random, they may contain biases or fail to generalize well to other populations.

\section{Conclusions}

Among patients with a VTE diagnosis in the United States, approximately $28 \%$ have a bleeding event within 1 year of the VTE event, and about half of these patients experience MB. MB is associated with a substantial medical cost and its clinical impact is severe, and thus it represents a significant burden among VTE patients in the real-world setting.

\section{Authors}

ALPESH AMIN, MD, is Chair, Department of Medicine, and Executive Director, Hospitalist Program, University of California, Irvine; AMANDA BRUNO, PhD, MPH, is Director, CV Health Economics \& Outcomes Research, U.S. Medical, Bristol-Meyers Squibb, Plainsboro, New Jersey; and JEFFREY TROCIO, MPH, is Director, Global Value \& Health Outcomes \& Evidence, Pfizer, New York, New York. JAY LIN, PhD, MBA, is Managing Director, and MELISSA LINGOHR-SMITH, PhD, is Research Investigator, Novosys Health, Green Brook, New Jersey.

AUTHOR CORRESPONDENCE: Alpesh Amin, MD, Chair, Department of Medicine, School of Medicine, University of California, Irvine, UCIMC, 101 The City Drive South, Bldg. 58, Rm 110, ZC-4076H, Mail Code: 4076, Irvine, CA 92868.

E-mail:anamin@uci.edu.
3. Prandoni P, Noventa F, Ghirarduzzi A, et al. The risk of recurrent venous thromboembolism after discontinuing anticoagulation in patients with acute proximal deep vein thrombosis or pulmonary embolism. A prospective cohort study in 1,626 patients. Haematologica. 2007;92(2):199-205. Available at: http://www.haematologica.org/content/92/2/199.long. Accessed September 10, 2015.

4. Heit JA, Mohr DN, Silverstein MD, Petterson TM, O'Fallon WM, Melton LJ 3rd. Predictors of recurrence after deep vein thrombosis and pulmonary embolism: a population-based cohort study. Arch Intern Med. 2000;160(6):761-68.

5. Kearon C, Akl EA, Comerota AJ, et al; American College of Chest Physicians. Antithrombotic therapy for VTE disease: antithrombotic therapy and prevention of thrombosis, 9th ed.: American College of Chest Physicians evidence-based clinical practice guidelines. Chest. 2012;141(2 Suppl):e419S-94S. Available at: http://www.ncbi.nlm.nih.gov/pmc/articles/PMC3278049/. Accessed September 10, 2015.

6. Friedman RJ. Benefits of novel oral anticoagulant agents for thromboprophylaxis after total hip or knee arthroplasty. Am Health Drug Benefits. 2012;5(2):115-22. Available at: http://www.ncbi.nlm.nih.gov/pmc/articles/ PMC4046449/. Accessed September 10, 2015

7. Schulman S, Kearon C, Kakkar AK, et al. Dabigatran versus warfarin in the treatment of acute venous thromboembolism. N Engl J Med. 2009;361:2342-52. Available at: http://www.nejm.org/doi/full/10.1056/ NEJMoa0906598. Accessed September 10, 2015.

8. Schulman S, Kakkar AK, Goldhaber SZ, et al. Treatment of acute venous thromboembolism with dabigatran or warfarin and pooled analysis. Circulation. 2014;129(7):764-72. Available at: http://circ.ahajournals.org/content/129/7/764.long. Accessed September 10, 2015

9. EINSTEIN Investigators, Bauersachs R, Berkowitz SD, et al. Oral rivaroxaban for symptomatic venous thromboembolism. N Engl J Med. 2010;363(26):2499-510. Available at: http://www.nejm.org/doi/full/10.1056/ NEJMoal007903. Accessed September 10, 2015.

10. EINSTEIN-PE Investigators, Buller HR, Prins MH, et al. Oral rivaroxaban for the treatment of symptomatic pulmonary embolism. N Engl J Med. 2012;366(14):1287-97. Available at: http://www.nejm.org/doi/full/10.1056/ NEJMoal113572. Accessed September 10, 2015.

11. Prins MH, Lensing AWA, Bauersachs R, et al. Oral rivaroxaban versus standard therapy for the treatment of symptomatic venous thromboembolism: a pooled analysis of the EINSTEIN-DVT and PE randomized studies. Thromb J. 2013;11(1):21. Available at: http://www.ncbi.nlm.nih.gov/pmc/ articles/PMC3850944/. Accessed September 10, 2015.

12. Agnelli G, Buller HR, Cohen A, et al. Oral apixaban for the treatment of acute venous thromboembolism. N Engl J Med. 2013;369(9):799-808. Available at: http://www.nejm.org/doi/full/10.1056/NEJMoal302507. Accessed September 10, 2015.

13. The Hokusai-VTE Investigators, Buller HR, Décousus H, et al. Edoxaban versus warfarin for the treatment of symptomatic venous thromboembolism. N Engl J Med. 2013;369(15):1406-15. Available at: http://www.nejm.org/doi/ full/10.1056/NEJMoa1306638. Accessed September 10, 2015.

14. Spyropoulos AC, Lin J. Direct medical costs of venous thromboembolism and subsequent hospital readmission rates: an administrative claims analysis from 30 managed care organizations. J Manag Care Pharm. 2007;13(6):475-86. Available at: http://www.amcp.org/data/jmcp/pages\%20475-86.pdf.

15. Lefebvre P, Laliberté F, Nutescu EA, et al. All-cause and potentially disease-related health care costs associated with venous thromboembolism in commercial, Medicare, and Medicaid beneficiaries. J Manag Care Pharm. 2012;18(5):363-74. Available at: http://www.amcp.org/WorkArea/ DownloadAsset.aspx?id=15288.

16. Deitelzweig SB, Pinsky B, Buysman E, et al. Bleeding as an outcome among patients with nonvalvular atrial fibrillation in a large managed care population. Clin Ther. 2013;35(10):1536-45. 
17. Bureau of Labor Statistics, U.S. Department of Labor. Consumer Price Index-December 2013. USDL-14-0037. Available at: http://www.bls.gov/ news.release/archives/cpi_01162014.pdf. Accessed September 10, 2015.

18. Amin A, Jing Y, Trocio J, Lin J, Lingohr-Smith M, Graham J. Evaluation of medical costs associated with use of new oral anticoagulants compared with standard therapy among venous thromboembolism patients. J Med Econ. 2014;17(11):763-70.

19. Spencer FA, Emery C, Joffe SW, et al. Incidence rates, clinical profile, and outcomes of patients with venous thromboembolism. The Worcester VTE study. J Thromb Thrombolysis. 2009;28(4):401-09. Available at: http://www. ncbi.nlm.nih.gov/pmc/articles/PMC3248815/. Accessed September 10, 2015.

20. Bullano MF, Willey V, Hauch O, Wygant G, Spyropoulos AC, Hoffman L. Longitudinal evaluation of health plan cost per venous thromboembolism or bleed event in patients with a prior venous thromboembolism event during hospitalization. J Manag Care Pharm. 2005;11(8):663-73. Available at: http:// www.amcp.org/data/jmcp/Original\%20Research\%20663-673.pdf.
21. Mercaldi CJ, Ciarametaro M, Hahn B, et al. Cost efficiency of anticoagulation with warfarin to prevent stroke in Medicare beneficiaries with nonvalvular atrial fibrillation. Stroke. 2011;42(1):112-18. Available at: http://stroke. ahajournals.org/content/42/1/112.long. Accessed September 10, 2015.

22. Nieto JA, Camara T, Gonzalez-Higueras E, et al. Clinical outcome of patients with major bleeding after venous thromboembolism. Findings from the RIETE registry. Thromb Haemost. 2008;100(5):789-96.

23. Hansson PO, Sörbo J, Eriksson H. Recurrent venous thromboembolism after deep vein thrombosis: incidence and risk factors. Arch Intern Med. 2000;160(6):769-74.

24. Hass B, Pooley J, Harrington AE, Clemens A, Feuring M. Treatment of venous thromboembolism-effects of different therapeutic strategies on bleeding and recurrence rates and considerations for future anticoagulant management. Thromb J. 2012;10(1):24. Available at: http://www.ncbi.nlm. nih.gov/pmc/articles/PMC3554503/. Accessed September 10, 2015. 